\title{
Proceeding
}

Supplementary Issue: Summer Conferences of Sports Science. $8^{\text {th }}$ International Workshop and Conference of the International Society of Performance Analysis of Sport (ISPAS), 11-1 th of September 2019 (Budapest, Hungary) "Technology meets Practice and Science".

\section{Differences in biological age of the best U11 and U13 teams in Croatia}

\author{
HRVOJE AJMAN $\triangle$, ZVONIMIR TOMAC \\ Faculty of Education, University Josip Juraj Strossmayer, Osijek, Croatia
}

\begin{abstract}
It is well known that among the individuals who are chronologically at the same age there are individuals who develop below the average as well as those above the average. The data on the level of biological development, are very important for the young athletes in sports. The aim of this research was to determine differences in biological age between male soccer players in the category U11 and U13 of the two best Croatian teams in the year 2011. The estimate for biological age was conducted by a validated questionnaire developed by the authors from the United Kingdom. Gender-specific, pubertal development self-assessment questionnaires were used photographs of the Tanner standards. For all participants anthropometrical characteristics (height, weight and BMI) were determined. For all samples descriptive parameters were calculated and Mann- Whitney $U$ test was used to determine differences. Statistically significant differences weren't determined in morphological variables. Statistically significant differences were determined only in U11 category in Tanner 1 . side standards $(U=27,50 ; p=0.00)$, and in 2. side $(U=41,50 ; p=0,01)$ but not in the $\mathrm{U} 13$ category $(\mathrm{p}=0.40)$. Statistically significant differences were determined in U11 category and maybe at this age that was a factor who had a significant impact on the final result of the championship. Keywords: Biological age; Football; Youth teams.
\end{abstract}

\section{Cite this article as:}

Ajman, H., \& Tomac, Z. (2019). Differences in biological age of the best U11 and U13 teams in Croatia. Journal of Human Sport and Exercise, 14(5proc), S2375-S2379. doi:https://doi.org/10.14198//hse.2019.14.Proc5.52

Corresponding author. Faculty of Education, University Josip Juraj Strossmayer, Osijek, Croatia.

E-mail: hajman@foozos.hr

Supplementary Issue: Summer Conferences of Sports Science. $8^{\text {th }}$ International Workshop and Conference of the International Society of Performance Analysis of Sport (ISPAS), 11-13 th of September 2019 (Budapest, Hungary).

JOURNAL OF HUMAN SPORT \& EXERCISE ISSN 1988-5202

(c) Faculty of Education. University of Alicante

doi:10.14198/jhse.2019.14.Proc5.52 


\section{INTRODUCTION}

Many of positive changes in performance can be significantly affected by growth and maturational factors. Researchers have examined the influence of growth and maturation on physical performance in youth, but practical information on different classifications of maturational assessments are very limited. Potential interactions among size, maturity and skill are often overlooked as youth progress in a sport. Participation in youth team sports is based primarily on chronological age groups of young athletes. Variation in size and skill associated with age and maturity can make a great difference in an early sport stage. Chronological age, which is calculated as a single time point away from the date of birth, has traditionally been used in sports to group age grade teams. However, literature has clearly demonstrated that individuals of the same chronological age can differ significantly with respect to biological maturity (Baxter-Jones, Eisenmann, Sherar, 2005; Rowland, 2005). Biological maturation refers to progress toward a mature state and varies in timing and tempo (Beunen and Malina, 2008). Significant variance exists for the level, timing and tempo of biological maturation inter individuals. Dependent on these variables, children will be classified as biologically ahead of their chronological age (early-maturing individual), "on-time" with their chronological age (average mature), or behind their chronological age (late-maturing individual) (Malina, Bouchard, Bar-Or, 2004).

Aim of this paper is to determine differences in biological age between male soccer players in the category U11 and U13 of the two best Croatian teams in the year 2011.

\section{METHODS}

The study sample consisted of 36 soccer players of the team who won championship that year and 26 soccer players of the team who won $2^{\text {nd }}$ place. Sample of respondents was divided on two subsamples according to age. First subsample consisted 16 soccer players U11 team who won championship, average age $11.41 \pm$ 0.38 years and 13 soccer players $\mathrm{U} 11$ team who won $2^{\text {nd }}$ place, average age $11.48 \pm 0.32$.

Second subsample consisted 20 soccer players U13 team who won championship, average age 13,46 \pm 0,46 and 13 soccer players U13 team who won $2^{\text {nd }}$ place, average age $13,26 \pm 0,27$ years. The estimate for biological age was conducted by a validated questionnaire developed by Taylor, et al., 2001. Gender-specific, pubertal development self-assessment questionnaires were used photographs of the Tanner standards (Tanner, 1962.).

\section{Tanner Criteria}

Sexual age refers to the degree of biological maturation toward fully functional reproductive capability (Malina, Bouchard, Bar-Or, 2004). Sexual maturation has been assessed through observations of secondary sexual characteristics (breast, genitalia, and pubic hair development), which are then compared against 5 distinct reference "stages," referred to as Tanner stages 1 (TS1), TS2, TS3, TS4, and TS5 (Tanner, 1962).

Specifically, observation of male characteristics would include genital and pubic hair development (Tanner, Preece, 1989). Ethical approval was obtained, and written consent from both parent and child. For all participants morphological characteristics (height, weight, BMI) were determined. Descriptive parameters were calculated for subsamples and Mann- Whitney $U$ test was used to determine differences between subsamples on the 0.5 level. 


\section{RESULTS AND DISCUSSION}

Descriptive parameters are presented in Table 1. for U11 category.

Table 1. Descriptive parameters for U13 category.

\begin{tabular}{|l|l|l|l|l|l|l|l|l|l|l|l|l|}
\hline \multirow{2}{*}{ U11 } & \multicolumn{9}{|l|}{ Champions } & \multicolumn{1}{l|}{ Vice-champions } & & \\
\cline { 2 - 14 } & Mean & SD & Min & Max & Mean & SD & Min & Max & $\begin{array}{l}\text { Rank Sum } \\
\text { Champions }\end{array}$ & $\begin{array}{l}\text { Rank Sum } \\
\text { Vice- } \\
\text { champions }\end{array}$ & $U$ \\
\hline Body height & 147.45 & 4.55 & 139.40 & 154.00 & 148.35 & 7.24 & 139.50 & 165.50 & 246.00 & 189.00 & 98.00 & 0.81 \\
\hline Body weight & 40.48 & 4.05 & 35.60 & 49.70 & 39.68 & 5.17 & 34.20 & 47.40 & 261.00 & 174.00 & 83.00 & 0.37 \\
\hline BMl & 18.62 & 1.72 & 17.05 & 24.07 & 18.04 & 2.11 & 14.80 & 22.73 & 254.00 & 181.00 & 90.00 & 0.55 \\
\hline 1. side & 3.19 & 0.83 & 2.00 & 4.00 & 1.77 & 0.83 & 1.00 & 3.00 & 316.50 & 118.50 & 27.50 & $0.00^{*}$ \\
\hline 2. side & 2.06 & 0.44 & 1.00 & 3.00 & 1.38 & 0.51 & 1.00 & 2.00 & 302.50 & 132.50 & 41.50 & $0.01^{*}$ \\
\hline
\end{tabular}

Descriptive parameters for U13 category are presented in Table 2.

Table 2. Descriptive parameters for U13 category.

\begin{tabular}{|c|c|c|c|c|c|c|c|c|c|c|c|c|}
\hline \multirow[b]{2}{*}{ U13 } & \multicolumn{4}{|c|}{ Champions } & \multicolumn{4}{|c|}{ Vice-champions } & \multirow[b]{2}{*}{$\begin{array}{l}\text { Rank Sum } \\
\text { Champions }\end{array}$} & \multirow[b]{2}{*}{$\begin{array}{l}\text { Rank Sum } \\
\text { Vice } \\
\text { champions }\end{array}$} & \multirow[b]{2}{*}{$U$} & \multirow[b]{2}{*}{$p$} \\
\hline & Mean & SD & Min & Max & Mean & SD & Min & Max & & & & \\
\hline Body height & 164.47 & 9.81 & 151.60 & 185.10 & 160.64 & 9.44 & 150.20 & 174.30 & 372.50 & 188.50 & 97.50 & 0.24 \\
\hline Body weight & 51.90 & 8.84 & 37.10 & 68.90 & 48.48 & 9.13 & 37.30 & 62.90 & 376.00 & 185.00 & 94.00 & 0.19 \\
\hline BMI & 19.05 & 1.44 & 15.64 & 22.09 & 18.61 & 1.55 & 16.43 & 21.64 & 364.00 & 197.00 & 106.00 & 0.39 \\
\hline 1. side & 3.50 & 0.83 & 2.00 & 5.00 & 3.23 & 1.01 & 2.00 & 5.00 & 363.50 & 197.50 & 106.50 & 0.40 \\
\hline 2. side & 3.30 & 0.92 & 2.00 & 5.00 & 2.69 & 1.18 & 1.00 & 4.00 & 374.00 & 187.00 & 96.00 & 0.22 \\
\hline
\end{tabular}

Players in U11 category are not statistically different according to body height (147.45 vs $145.35 \mathrm{~cm}$ ), body weight (40.48 vs $39.68 \mathrm{~kg}$ ) and BMl (18.62 vs 18.04) variables. However, in variables of biological age, which was tested by Tanner criteria, there are statistically significant differences between league champions and vice-champions. League champions were biologically older than vice-champions.

Even though the changes in puberty happen continuously they are for the clinical purposes divided into stages based on the level of secondary sex characteristics development (Whincup, et al., 1992.). The level of sexual maturity, known as Tanner classification, is based on the scale of secondary sex characteristics, which allows scientists to determine the level of pubertal development in which the adolescent is at the moment, independent of his/her chronological age (Tanner, 1962).

Table 3. Results of Tanner criteria divided by subsamples.

\begin{tabular}{|l|l|l|l|}
\hline & Tanner & Mean & SD \\
\hline \multirow{2}{*}{ Champions U11 } & 1. side & 3,19 & 0,83 \\
\cline { 2 - 4 } & 2. side & 2,06 & 0,44 \\
\hline \multirow{2}{*}{ Vice-Champions U11 } & 1. side & 1,77 & 0,83 \\
\cline { 2 - 4 } & 2. side & 1,38 & 0,51 \\
\hline \multirow{2}{*}{ Champions U13 } & 1. side & 3,50 & 0,83 \\
\cline { 2 - 4 } & 2. side & 3,30 & 0,92 \\
\hline \multirow{2}{*}{ Vice-Champions U13 } & 1. side & 3,23 & 1,01 \\
\cline { 2 - 4 } & 2. side & 2,69 & 1,18 \\
\hline
\end{tabular}


The first stage includes the prepubertal growth and development. The stage 2 indicates the initial appearance and the beginning of secondary sex characteristics development - with boys it means initial growth of genitalia with the appearance of pubic hair. The stage 3 and 4 are so-called stages of medium puberty where adolescents develop further regarding their secondary sex characteristics. The sexual maturity is completed up to the stage 5 and this is the stage that indicates the level of sexual maturity of an adult (Tanner, 1962). The U11 subsample, championship winners, participating in this research are dominantly in 2 or 3 stage of the biological development, while the subjects in subsample of vice-champions are still in 1 stage of biological development. The U13 subsample both championship winners and vice-champions, participating in this research are mostly in 3 stage of the biological development (Table 3 ).

In the study of Spanish football players, for example, only 7 of 43 (24\%) 13-year-old players were in genital stages 4 and higher, (Rovira et al., 1991). Although stages of pubic hair and genital development are not equivalent, the data for Spanish football players are generally consistent in showing advanced maturity in adolescent players. Spanish players, according to results of this study are in higher biological development stage than Croatian players.

\section{CONCLUSIONS}

Statistically significant differences in biological age were determined in U11 category. Players from other European leagues, according to results of this study, are in higher biological development stage than Croatian players. According to results of the U11 subsample, championship winners, participating in this research are dominantly in 2 or 3 stage of the biological development, while the subjects in subsample of vice-champions are still in stage 1 of biological development. These results indicate that in the age of 11 years there are great differences in biological age between players and maybe at this age that was a factor who had a significant impact on the final result of the championship. At the age of 13 years, differences are not such significant.

\section{REFERENCES}

Baxter-Jones, A. D., Eisenmann, J. C., \& Sherar, L. B. (2005). Controlling for maturation in pediatric exercise science. Pediatric Exercise Science, 17(1), 18-30. https://doi.org/10.1123/pes.17.1.18

Rowland, T. W. (2005). Children's exercise physiology (pp. 67-133). Champaign, IL: Human Kinetics.

Beunen, G., \& Malina, R. M. (2008). Growth and biologic maturation: relevance to athletic performance. H. Hebestreit, O. Bar-Or, The young athlete Massachusetts: Blackwell Publishing, 3-18. https://doi.org/10.1002/9780470696255.ch1

Malina, R. M., Bouchard, C., \& Bar-Or, O. (2004). Growth, maturation, and physical activity. Human kinetics.

Rovira, A. F., Peman, M. A., Cartasona, C. B., Martinez, F. B., Bllart, J. F., \& Henneberg, C. M. (1991). Predicción de la capacidad física de deportistas durante la pubertad: Análisis en futbolistas de alto rendimento. Anales Españoles de Pediatría, 5(35), 323-6.

Taylor, S. J., Whincup, P. H., Hindmarsh, P. C., Lampe, F., Odoki, K., \& Cook, D. G. (2001). Performance of a new pubertal self-assessment questionnaire: a preliminary study. Paediatric and perinatal epidemiology, 15(1), 88-94. https://doi.org/10.1046/i.1365-3016.2001.00317.x

Tanner, J. (1962). Growth at adolescence: With a general consideration of the effects of 512 hereditary and environmental factors upon growth and maturation from birth to 513 maturity. Blackwell Scientific: Oxford, England, 514, 515.

Tanner, J. M., \& Preece, M. A. (Eds.). (1989). The physiology of human growth (No. 29). Cambridge University Press. 
Whincup, P. H., Cook, D. G., Papacosta, O., \& Walker, M. (1992). Childhood blood pressure, body build, and birthweight: geographical associations with cardiovascular mortality. Journal of Epidemiology \& Community Health, 46(4), 396-402. https://doi.org/10.1136/jech.46.4.396

\section{(c) 7 (†) $९$}

This work is licensed under a Attribution-NonCommercial-NoDerivatives 4.0 International (CC BY-NC-ND 4.0). 